\title{
On the Stator Slot Geometry of a Cable Wound Generator for Hydrokinetic Energy Conversion
}

\author{
Mårten Grabbe, Sandra Eriksson, and Mats Leijon \\ The Swedish Centre for Renewable Electric Energy Conversion, Division of Electricity, The Angström Laboratory, \\ Uppsala University, P.O. Box 534, 75121 Uppsala, Sweden
}

Correspondence should be addressed to Sandra Eriksson; sandra.eriksson@angstrom.uu.se

Received 17 June 2014; Accepted 5 October 2014

Academic Editor: Linni Jian

Copyright (C) 2015 Mårten Grabbe et al. This is an open access article distributed under the Creative Commons Attribution License, which permits unrestricted use, distribution, and reproduction in any medium, provided the original work is properly cited.

The stator slot geometry of a cable wound permanent magnet synchronous generator for hydrokinetic energy conversion is evaluated. Practical experience from winding two cable wound generators is used to propose optimized dimensions of different parts in the stator slot geometry. A thorough investigation is performed through simulations of how small geometrical changes alter the generator performance. The finite element method (FEM) is used to model the generator and the simulations show that small changes in the geometry can have large effect on the performance of the generator. Furthermore, it is concluded that the load angle is especially sensitive to small geometrical changes. A new generator design is proposed which shows improved efficiency, reduced weight, and a possibility to decrease the expensive permanent magnet material by almost one-fifth.

\section{Introduction}

The permanent magnet geometry and stator slot geometry are important design parameters in the magnetic circuit of an electrical machine. In addition, utilizing cable winding presents new stator slot geometries that have not previously been studied in great detail. In this paper, the stator slot design of a cable wound permanent magnet synchronous generator for hydrokinetic energy conversion is studied using finite element (FE) simulations. The importance of changes on the millimetre scale in the stator slot geometry is discussed based on the practical experience from the design and the assembly of two prototypes.

The generator is designed to be directly connected to a fixed pitch vertical axis turbine, operating at both variable speed and power to electrically control the tip speed ratio of the turbine [1]. The generator is also intended to efficiently brake the turbine at water velocities above nominal operation, implying that a low load angle at nominal operation is preferable. Other direct drive designs for tidal turbines have been proposed recently; see, for instance, [2-6], but as the focus is on the stator slot geometry, the work presented here is more closely related to studies on other cable wound machine designs for wind power [7], wave power [8], and the high voltage Powerformer [9].

The starting point, or reference geometry, is that of the first prototype presented in [10], rated at $5 \mathrm{~kW}$ and $150 \mathrm{~V}$ at $10 \mathrm{rpm}$. As with most early prototypes, the generator design at hand can most likely be improved in many aspects. In this study, however, the focus is on possible performance gains by changing the stator slot geometry in the existing design. In order to incorporate practical experience from construction of two prototypes, the influence of one parameter at a time is discussed rather than a traditional optimization study. Such improvements would likely be relevant even if other parameters in the design would be changed.

\section{Reference Machine Characteristics}

The $5 \mathrm{~kW}$ reference machine has 120 poles and is designed for the low velocities presented by tidal currents. Surface mounted $\mathrm{Nd}_{2} \mathrm{Fe}_{14} \mathrm{~B}$ magnets are used and the stator is stacked with laser cut M800-100A sheets with a single row of six $16 \mathrm{~mm}^{2}$ cables in each slot as seen in Figure 1.

The magnet width and slot opening design of the reference machine have largely evolved from a previous study of 


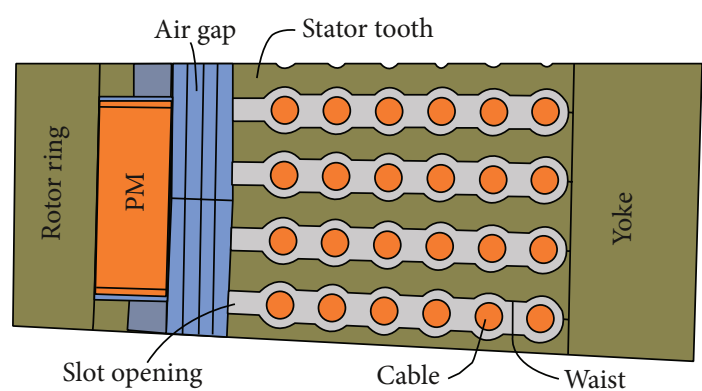

FIGURE 1: The geometry used in the FE model of the reference machine.

TABLE 1: Reference machine main design parameters.

\begin{tabular}{lc}
\hline Power & $5 \mathrm{~kW}$ \\
Voltage & $150 \mathrm{~V}$ \\
Rotational speed & $10 \mathrm{rpm}$ \\
Number of poles & 120 \\
Fractional winding & $7 / 5$ \\
Stator outer diameter & $2000 \mathrm{~mm}$ \\
Stator inner diameter & $1835 \mathrm{~mm}$ \\
Air gap & $10.5 \mathrm{~mm}$ \\
Machine length & $270 \mathrm{~mm}$ \\
Magnet height & $13 \mathrm{~mm}$ \\
Magnet width & $32 \mathrm{~mm}$ \\
PM remanence & $1.22 \mathrm{~T}$ \\
\hline
\end{tabular}

TABLE 2: Stator slot geometry of the reference machine compared to the suggested improved geometry.

\begin{tabular}{lcc}
\hline Parameter & Reference & New design \\
\hline Slot opening & $4 \mathrm{~mm}$ & $4 \mathrm{~mm}$ \\
Slot width $\left(w_{\text {slot }}\right)$ & $8 \mathrm{~mm}$ & $7.6 \mathrm{~mm}$ \\
Cable diameter & $7 \mathrm{~mm}$ & $7 \mathrm{~mm}$ \\
Waist width $\left(w_{\text {waist }}\right)$ & $6 \mathrm{~mm}$ & $6.1 \mathrm{~mm}$ \\
Waist factor & 0.75 & 0.8 \\
Cable to cable $\left(d_{c-c}\right)$ & $2 \mathrm{~mm}$ & $0.8 \mathrm{~mm}$ \\
Cable to air gap $\left(d_{c-a}\right)$ & $5.5 \mathrm{~mm}$ & $1.3 \mathrm{~mm}$ \\
Cable to stator $\left(d_{c-s}\right)$ & $0.5 \mathrm{~mm}$ & $0.3 \mathrm{~mm}$ \\
Slot depth & $58 \mathrm{~mm}$ & $47.6 \mathrm{~mm}$ \\
\hline
\end{tabular}

a cable wound linear generator [8]. In this case, however, the focus is on the interior geometry of the stator slots.

At first, it should be noted that the cable windings are not inserted radially from the air gap. Rather, the cable is inserted axially into each stator slot position and wound in a fractional (7/5) wave winding. No slot wedges are used, but instead the stator slot opening is narrow to prevent the cables from entering the air gap. Furthermore, a small waist is introduced between each cable to prevent them from rubbing against each other during the winding procedure and to keep them fixed in place during operation.
TABLE 3: Reference machine performance at its nominal operating point compared with the suggested improved design.

\begin{tabular}{lcc}
\hline Parameter & Reference & New design \\
\hline Efficiency & $86.4 \%$ & $87.0 \%$ \\
B in stator tooth & $1.69 \mathrm{~T}$ & $1.57 \mathrm{~T}$ \\
Hysteresis losses in teeth & $0.149 \mathrm{~kW}$ & $0.128 \mathrm{~kW}$ \\
Eddy current losses in teeth & $0.037 \mathrm{~kW}$ & $0.032 \mathrm{~kW}$ \\
Total losses & $0.785 \mathrm{~kW}$ & $0.748 \mathrm{~kW}$ \\
Load angle & $7.5^{\circ}$ & $6.2^{\circ}$ \\
Stator weight & $598 \mathrm{~kg}$ & $532 \mathrm{~kg}$ \\
\hline
\end{tabular}

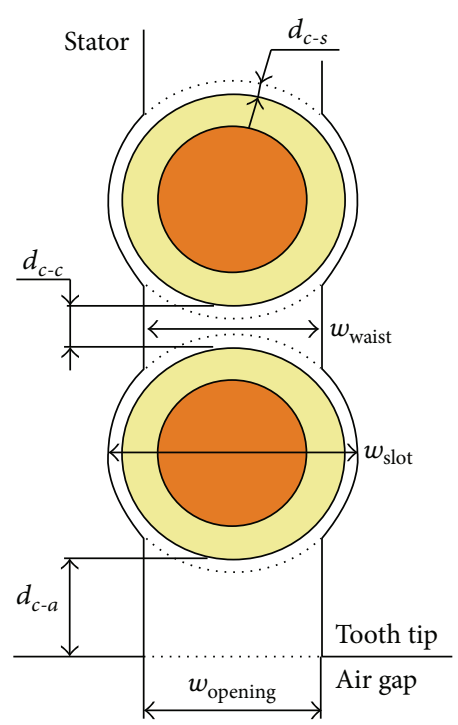

FIgURE 2: A stator slot opening and the two cables closest to the air gap showing the geometry parameters used in this study.

The main characteristics of the reference generator are presented in Table 1. The stator slot geometry is detailed in column one of Table 2 and Figure 2, and the resulting performance is summarized in the first column of Table 3.

\section{FE Model of the Generator}

The generator is designed with the aid of an in-house developed design tool and the combined set of field and circuit equations are solved in the finite element environment ACE [11]. The magnetic field inside the core of the generator is assumed to be axisymmetrical and modeled in two dimensions. The displacement field is neglected and the permanent magnets are modeled using the current sheet approach [12]. Furthermore, coil end impedances are introduced in the circuit equations, the laminated stator core is modeled using a singl-valued magnetization curve, and a correction factor of 1.5 is used for all iron losses.

The model used is described in more detail in [13] and simulations of the first prototype have been compared to experiments in [10]. The mesh includes around 33000 elements and second-order shape functions are used. 


\section{Simulations of the Stator Slot Geometry}

The parameters that are changed are the the waist $\left(w_{\text {waist }}\right)$, the distance between cables $\left(d_{c-c}\right)$, the distance between cable and air gap $\left(d_{c-a}\right)$, and the distance between cable and stator $\left(d_{c-s}\right)$, as shown in Figure 2.

Simulations are performed using the model presented in Section 3. One parameter at a time is changed, while all other parameters are fixed to their reference value. All computations are performed at nominal load and nominal speed. If the slot depth is changed, the stator outer diameter is adjusted accordingly to maintain the same yoke width. As the voltage and power are kept fixed, changes in the axial length are allowed. The changes are a few millimetres at most and are only presented indirectly through small changes in copper losses, iron losses, and stator weight.

The generator is intended to be used with a diode rectifier. In the simulations, the generator is connected to a purely resistive load, which corresponds to a power factor of unity as is the case with diode rectification. During the analysis, the voltage and power are kept constant. According to the circuit theory, the load angle, $\delta$, for a generator with unity power factor can be calculated as $\sin (\delta)=X I / E$, where $X$ is the synchronous reactance, $I$ is the current, and $E$ is the internal voltage. The change in load angle can therefore be seen as a direct measurement of change in the machine reactance.

4.1. Waist Design. In the reference case, the slot width is $8 \mathrm{~mm}$ and the waist is $6 \mathrm{~mm}$ at its narrowest point. The waist factor, defined as $w_{\text {waist }} / w_{\text {slot }}$, is thus 0.75 in the reference geometry.

A pronounced waist keeps the cable firmly in place and reduces the area in the tooth with high magnetic induction, thereby slightly reducing the iron losses. However, the waist also increases the leakage flux resulting in a higher load angle. As can be seen in Figure 3, no waist decreases the load angle but increases the hysteresis losses in the stator tooth. Without a waist, however, some other means of protecting the cables from rubbing against each other during winding would have to be implemented.

4.2. Cable to Cable. The distance between cables $\left(d_{c-c}\right)$ may have practical considerations during the winding procedure. Keeping the cables close to each other results in shorter stator teeth and a more compact design. However, if the cables are positioned too closely, a more pronounced waist may be required to prevent them from rubbing against each other during winding. The coil end positioning may also be affected by the distance between cables. A distance of $2 \mathrm{~mm}$ was used successfully in the reference machine, making a more compact design look viable.

Gains in both efficiency and load angle can be achieved by moving the cables closer to each other (see Figure 4). Perhaps more importantly, the stator weight and stator outer diameter can be reduced by $4 \%$ and $8 \mathrm{~mm}$, respectively. It should be noted though, that the same space would still be required for the coil ends.

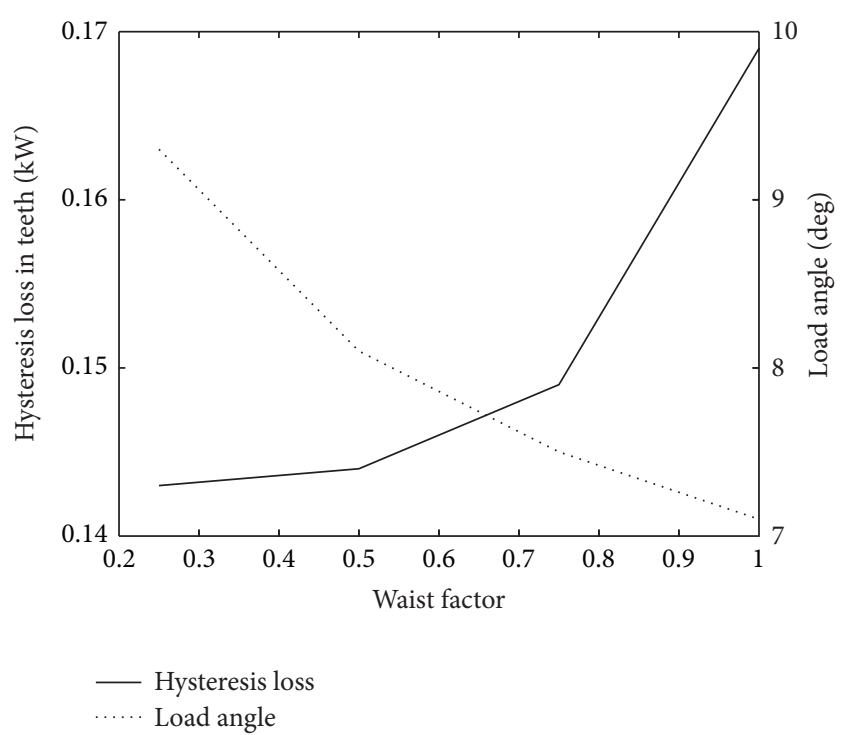

FIGURE 3: The hysteresis loss in the stator teeth and the load angle as a function of the waist factor.

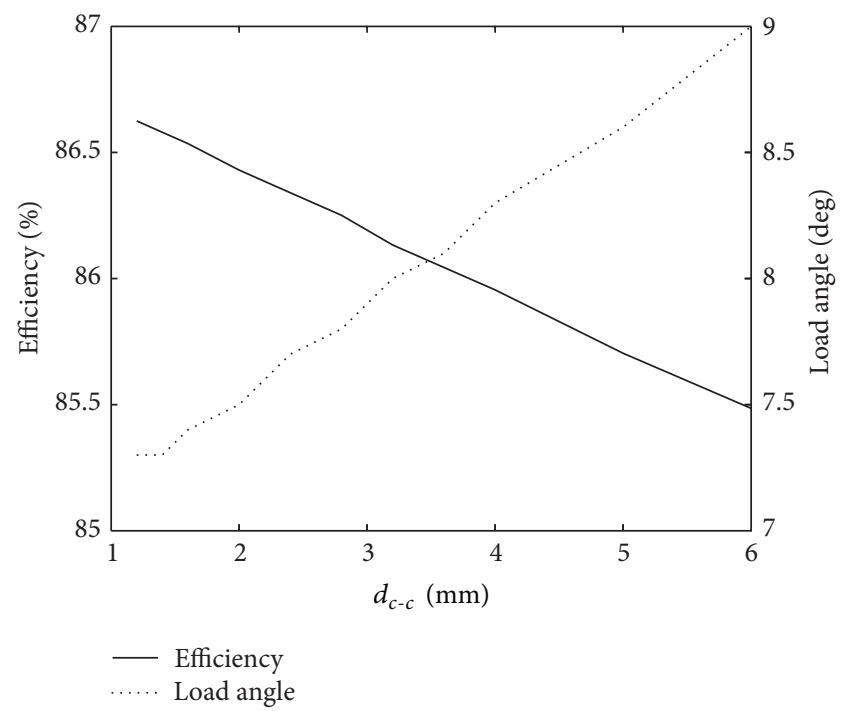

FIgURE 4: The efficiency and the load angle as a function of the distance between cables.

4.3. Cable to Air Gap. Moving the winding closer to the air gap is perhaps the most straight forward way to achieve a more compact design. One might have to consider, depending on winding scheme, if the coil ends need a certain space to the air gap. A distance of $5.5 \mathrm{~mm}$ from the air gap to the first cable position was chosen in the reference machine. It turned out to work well in practice, as the coil ends could be pushed backwards away from the air gap, leaving room for improvements in this area as well.

The distance to the air gap hardly affects the efficiency at nominal load conditions. However, as can be seen in Figure 5, the weight of the machine and load angle are both decreased as the windings are moved closer to the air gap. 


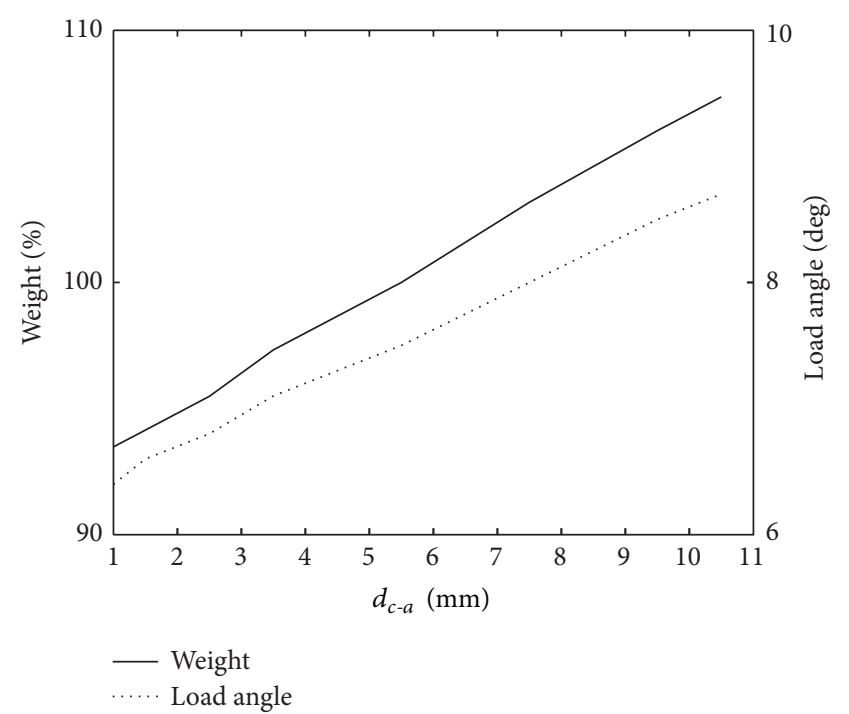

FIGURE 5: The change in weight and the load angle as a function of the distance from the winding to the air gap.

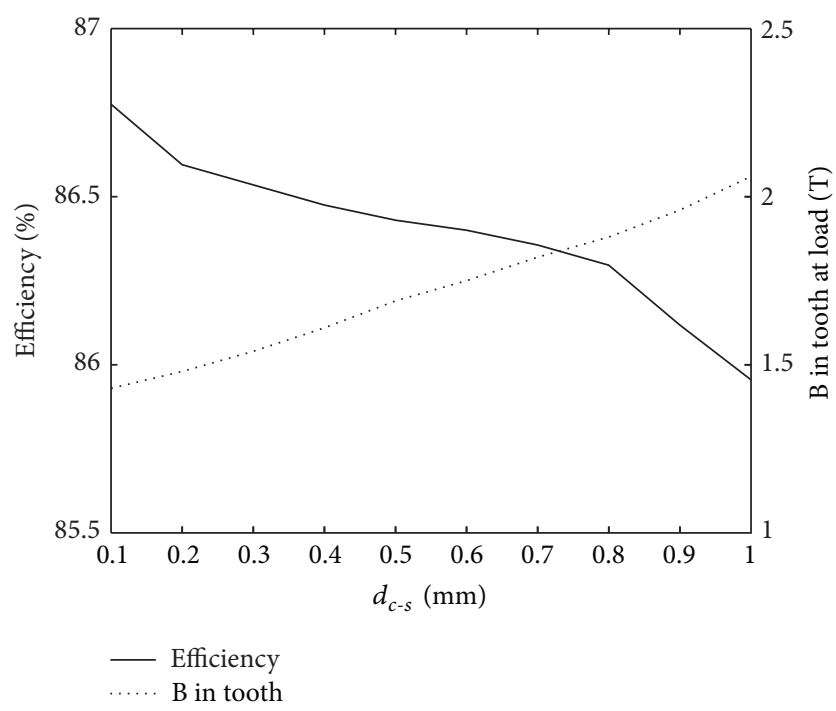

FIGURE 6: Efficiency and B-field in tooth at nominal load for varying distance between cable and stator.

4.4. Slot Width. The distance between the cable and the stator $\left(d_{c-s}\right)$ might be the single parameter that most clearly affects the winding procedure. Assuming the stator sheets are well aligned and properly stacked, a certain distance between the cable and the stator is still needed to allow for a smooth and easy winding procedure. A too tight design might cause unnecessary wear on the cables.

Cables with a diameter of $7 \mathrm{~mm}$ were used to wind the reference machine with a slot width of $8 \mathrm{~mm}$ (i.e., $d_{c-s}=$ $0.5 \mathrm{~mm}$ ). The winding procedure went smoothly. It should however be noted that the prototype was wound by hand, and the distance between cable and stator might have to be reevaluated when utilizing industrial robots for automated winding [14].
The slot width is changed, which results in a new tooth width. Thus, clear changes are seen in the B-field in the stator tooth as $d_{c-s}$ is changed (see Figure 6). In other words, if a larger gap between cable and slot is needed, the design will also have to incorporate a slightly larger stator diameter to accommodate sufficiently wide stator teeth.

\section{Results and Discussion}

Incorporating all the small changes in the geometry discussed above may add up to a significant improvement. However, none of the predicted improvements would be worthwhile if it turned out to complicate the manufacturing and the assembly procedure.

Winding the reference machine went smoothly, most likely thanks to proper stacking and good alignment of the stator sheets. The result from the reference machine has validated the results of the simulations as presented in [10]. This experience gave confidence to incorporate some changes in the second prototype [15]. There, the winding was moved closer to the air gap $(2.4 \mathrm{~mm}$ instead of $5.5 \mathrm{~mm})$, the cables were moved closer to each other $(1 \mathrm{~mm}$ instead of $2 \mathrm{~mm}$ ), and the gap between cable and stator was decreased to $0.4 \mathrm{~mm}$. Again, the winding procedure went smoothly without appreciable wear on the cable insulation.

Experience from winding the second prototype has given confidence that further incremental changes to the geometry may be implemented in practice. A tighter gap between cable and stator $(0.3 \mathrm{~mm})$ would render a less pronounced waist possible. Experience also indicate that the cables could be moved closer to the air gap $(1.3 \mathrm{~mm})$, further decreasing the slot depth and the generator outer diameter. The new stator slot design is shown in Figure 7 and compared to the reference machine in Tables 2 and 3. The proposed changes would, according to simulations, improve the efficiency from $86.4 \%$ to $87.0 \%$ and lower the load angle from $7.5^{\circ}$ to $6.2^{\circ}$. Perhaps more significantly, the stator weight would be decreased by $11 \%$, and the outer diameter would be decreased by $20.4 \mathrm{~mm}$ allowing for further savings on the support structure.

The decrease in load angle can be translated into either a decrease in magnetic material necessary to maintain the nominal design point of $150 \mathrm{~V}$ and $5 \mathrm{~kW}$ at a load angle of $7.5^{\circ}$, or an increase in power output at the same voltage and load angle as the reference machine. Simulations predict that the new design can reach the nominal design point utilizing $19 \%$ less permanent magnet material, or a $22 \%$ increase in electrical power output at the reference voltage and load angle.

\section{Conclusions}

The finite element analysis of the cable wound generator shows that the performance can be improved by apparently small changes in the stator slot geometry. A new design is proposed based on practical experience from winding two prototypes, and simulations predict an increase in efficiency of 0.6 percentage points, while the stator core weight is 


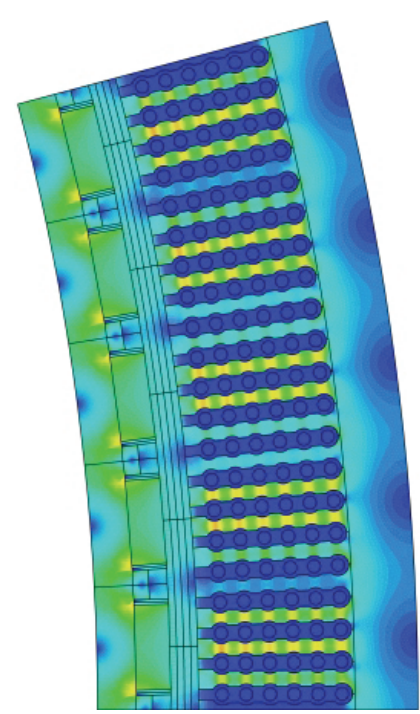

(a)

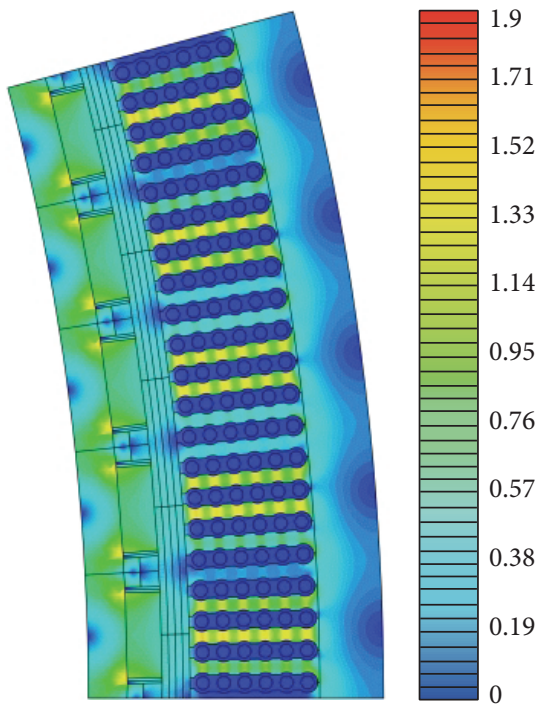

(b)

FIGURE 7: Illustration of the magnetic field distribution in the reference machine (to the left) and the new design (to the right).

reduced by $11 \%$ and the load angle is decreased by $17 \%$. The more compact design allows for further savings on the support structure. The decrease in load angle can be translated into a $19 \%$ decrease in magnetic material at the nominal design point. Finally, it can be concluded that the load angle is influenced by small alterations in the stator geometry. Therefore, a thorough evaluation of the stator slot geometry is important when optimizing a generator design.

\section{Conflict of Interests}

The authors declare that there is no conflict of interests regarding the publication of this paper.

\section{Acknowledgments}

The work reported was financially supported by the Swedish Centre for Renewable Electric Energy Conversion, STandUP for Energy and Swedish Research Council (Grant no. 6212009-4946). Construction of the prototype generators has been supported by Vattenfall AB, the Swedish Energy Agency, Ångpanneföreningen's Foundation for Research and Development (ÅForsk), and the J. Gust. Richert Foundation. The electrical design of the first prototype performed by Karin Thomas is deeply appreciated.

\section{References}

[1] K. Yuen, K. Thomas, M. Grabbe et al., "Matching a permanent magnet synchronous generator to a fixed pitch vertical axis turbine for marine current energy conversion," IEEE Journal of Oceanic Engineering, vol. 34, no. 1, pp. 24-31, 2009.

[2] M. Mueller, A. McDonald, K. Ochije, and J. Jeffrey, "A novel lightweight permanent magnet generator for direct drive power take off in marine renewable energy converters," in Proceedings of the 7th European Wave and Tidal Energy Conference (EWTEC '07), Porto, Portugal, 2007.

[3] L. Drouen, J. F. Charpentier, E. Semail, and S. Clenet, "Study of an innovative electrical machine fitted to marine current turbines," in Proceedings of the OCEANS 2007-Europe Conference, pp. 1-6, Aberdeen, Scotland, June 2007.

[4] J. Weilepp, "Progress in wave and tidal current technology," International Journal on Hydropower and Dams, vol. 16, no. 4, pp. 95-100, 2009.

[5] J. Clarke, G. Connor, A. Grant, C. Johnstone, and S. OrdonezSanchez, "Analysis of a single point tensioned mooring system for station keeping of a contra-rotating marine current turbine," IET Renewable Power Generation, vol. 4, no. 6, pp. 473-487, 2010.

[6] O. Keysan, A. S. McDonald, and M. Mueller, "A direct drive permanent magnet generator design for a tidal current turbine (SeaGen)," in Proceedings of the IEEE International Electric Machines and Drives Conference (IEMDC '11), pp. 224-229, May 2011.

[7] S. Eriksson, H. Bernhoff, and M. Leijon, "A $225 \mathrm{~kW}$ direct driven PM generator adapted to a vertical axis wind turbine," Advances in Power Electronics, vol. 2011, Article ID 239061, 7 pages, 2011.

[8] O. Danielsson, M. Leijon, and E. Sjöstedt, "Detailed study of the magnetic circuit in a longitudinal flux permanent-magnet synchronous linear generator," IEEE Transactions on Magnetics, vol. 41, no. 9, pp. 2490-2494, 2005.

[9] S. Alfredsson, B. Hernnäs, and H. Bergström, "Assembly of generators with rated voltage higher than $100 \mathrm{kV}$," in Proceedings of the International Conference on Power System Technology (PowerCon '00), vol. 1, pp. 189-193, 2000.

[10] K. Thomas, M. Grabbe, K. Yuen, and M. Leijon, "A lowspeed generator for energy conversion from marine currentsexperimental validation of simulations," Proceedings of the Institution of Mechanical Engineers Part A: Journal of Power and Energy, vol. 222, no. 4, pp. 381-388, 2008. 
[11] ACE User Manual, Modified Version 3.1, ABB Common Platform for Field Analysis and Simulations, ABB Corporate Research Centre, ABB AB, Västerås, Sweden, 2001.

[12] R. Gupta, T. Yoshino, and Y. Saito, "Finite element solution of permanent magnetic field," IEEE Transactions on Magnetics, vol. 26, no. 2, pp. 383-386, 1990.

[13] S. Eriksson, Direct Driven Generators for Vertical Axis Wind Turbines, Comprehensive Summaries of Uppsala Dissertations from the Faculty of Science and Technology, 2008.

[14] E. Hultman and M. Leijon, "Utilizing cable winding and industrial robots to facilitate the manufacturing of electric machines," Robotics and Computer-Integrated Manufacturing, vol. 29, no. 1, pp. 246-256, 2013.

[15] K. Yuen, S. Lundin, M. Grabbe, E. Lalander, A. Goude, and M. Leijon, "The Söderfors project: construction of an experimental hydrokinetic power station," in Proceedings of the 9th European Wave and Tidal Energy Conference (EWTEC '11), pp. 1-5, Southampton, UK, 2011. 


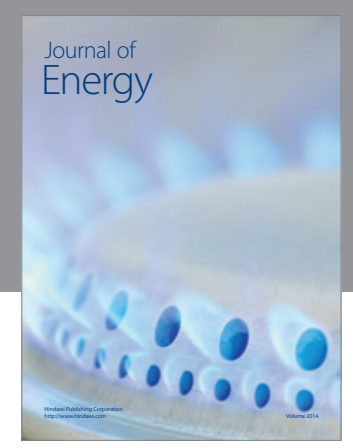

Journal of

Industrial Engineering
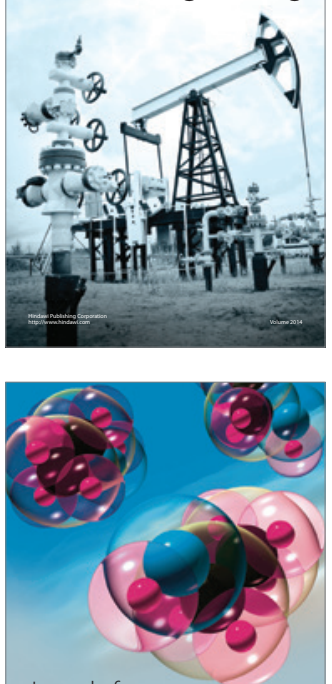

Fuels
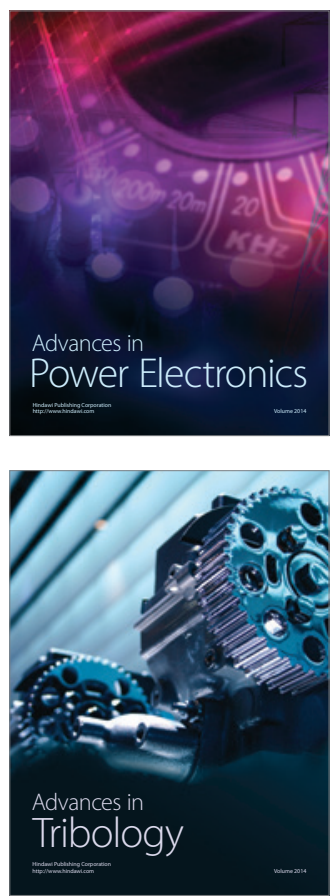

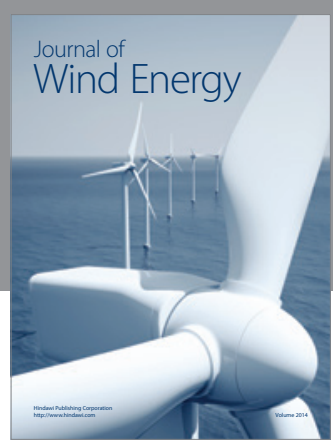

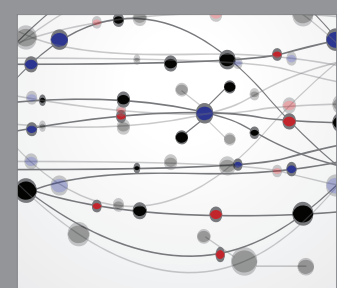

The Scientific World Journal

Submit your manuscripts at http://www.hindawi.com

Journal of

Structures
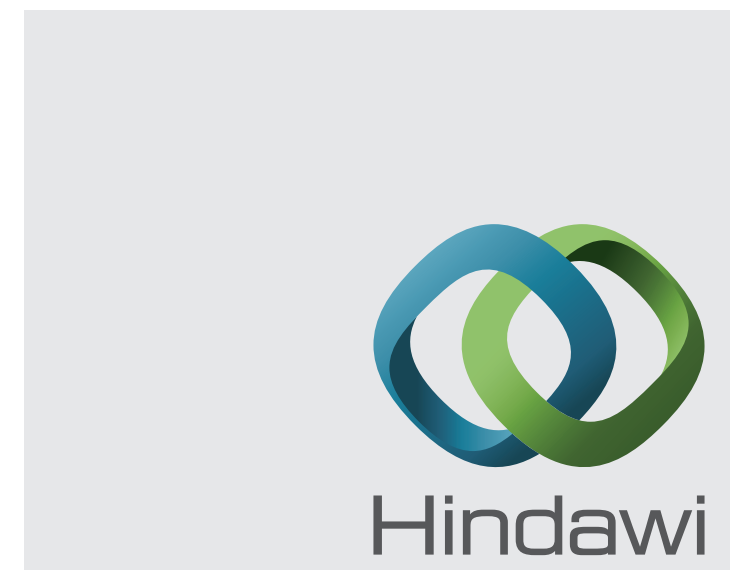

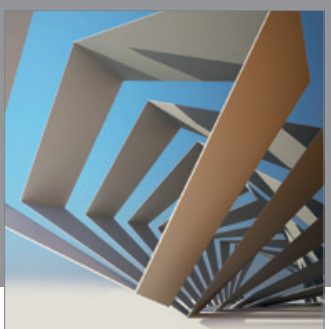

Rotating

Machinery
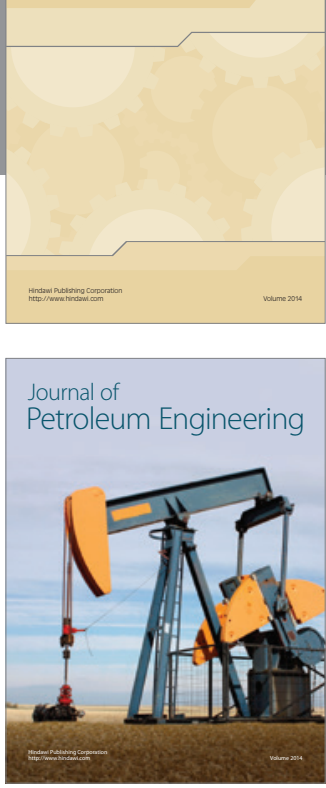

Journal of

Solar Energy
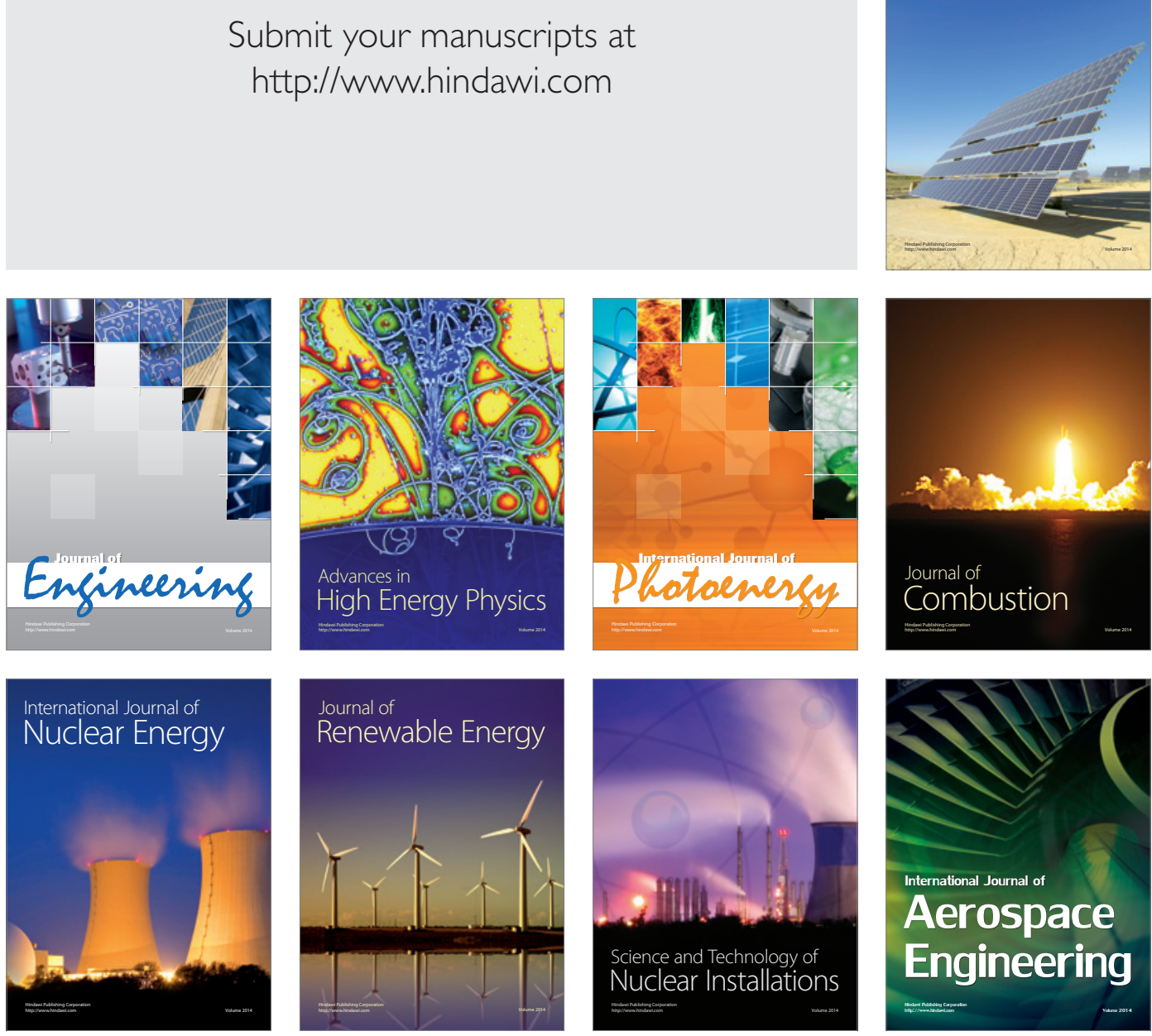